\title{
Industrial Kaolin Waste as Raw Material in the Synthesis of the SAPO-34 Molecular Sieve
}

\author{
Darllan do Rosario Pinheiro ${ }^{a}$ (D), Leonardo Rodrigues Gonçalves ${ }^{b}$, Raimunda Lina Pacheco de Sena , $^{b}$ \\ Marlice Cruz Martelli ${ }^{b}$, Roberto de Freitas Neves ${ }^{b}$, Nielson Fernando da Paixão Ribeiro ${ }^{b}$ \\ ${ }^{a}$ Universidade Federal do Pará - UFPA, Instituto de Tecnologia - ITEC, Programa de Pós-Graduação \\ em Engenharia de Recursos Naturais da Amazônia - PRODERNA, Rua Augusto Correa, 01, 66075-110, \\ Belém, PA, Brasil \\ ${ }^{b}$ Universidade Federal do Pará - UFPA, Instituto de Tecnologia - ITEC, Faculdade de Engenharia \\ Química - FEQ, Rua Augusto Correa, 01, 66075-110, Belém, PA, Brasil
}

Received: January 30, 2020; Revised: March 16, 2020; Accepted: March 30, 2020

\begin{abstract}
High-purity SAPO-34 was synthesized using industrial kaolin waste produced in the Amazon region as the main source of silicon and aluminium. The hydrothermal method was applied to investigate the effect of the $\mathrm{Si} / \mathrm{Al}$ ratio and crystallization time on the phase formation and purity. The materials were characterized by X-ray fluorescence, X-ray diffraction, thermogravimetric analysis, and scanning electron microscopy, which demonstrated that SAPO-34 with greater purity was obtained only for the composition whose $\mathrm{Si} / \mathrm{Al}$ ratio was approximately 1 , which was obtained by inserting $\mathrm{Al}_{2} \mathrm{O}_{3}$ into the synthesis gel.
\end{abstract}

Keywords: kaolin waste, SAPO-34, synthesis, characterization.

\section{Introduction}

Silicoaluminophosphates (SAPOs) are a class of synthetic molecular sieves widely used in catalytic processes due to the acid characteristics of their active sites. SAPO-34 stands out for having moderate acid strength, which favours its use in various types of reactions ${ }^{1}$. SAPO-34 has been used with success in methanol-to-olefin (MTO) or dimethyl-ether-to-olefins (DTO) reaction ${ }^{2,3}$, selective catalytic reduction $\left(\mathrm{NH}_{3}-\mathrm{SCR}\right)$ of $\mathrm{NO}_{x}^{4}$, membranes for $\mathrm{CO}_{2}$ separations ${ }^{5,6}$, etc.

Most SAPO-34 synthesis methodologies use hydrothermal processes by applying analytical reagents. Usually, silicon sol and Aerosil silica are used as sources of silicon with pseudoboehmite or aluminium isopropoxide as the starting source for aluminium which makes the process more expensive and limited ${ }^{1}$. Phosphoric acid, water, and an structure directing agent (SDA) complete the synthesis gel. Wang et al. ${ }^{7}$, for example, used phosphoric acid and silica sol and pseudoboehmite as precursors and triethylamine as a SDA in the synthesis of SAPO-34. Singh et al. ${ }^{8}$ employed pseudoboehmite, Aerosil silica, and orthophosphoric acid as starting materials in the production of SAPO-34 and morpholine as an SDA.

The search for alternative sources is relevant to evaluate the possibility of synthesis of different molecular sieves. The Industrial kaolin waste is a reject from beneficiation stage produced in large-scale and deposited in open-pit lagoons. Due to its physicochemical characteristics it is highly promising to be used as a source of silicon and aluminium, besides being low cost and abundant. Hildebrando et al. ${ }^{9}$, Silva et al. ${ }^{10}$, and Maia et al. ${ }^{11}$ used kaolin waste from the

*e-mail: darllandorosario@gmail.com
Amazon as a precursor of various zeolites and obtained excellent synthesis products.

In this current study, we have reported the synthesis of high quality SAPO-34 using the hydrothermal route with industrial kaolin waste as a new source of silicon and aluminum. The effect of the $\mathrm{SiO}_{2} / \mathrm{Al}_{2} \mathrm{O}_{3}$ ratio with or without aluminum external source adjustment and crystallization time on the phase purity of the synthesized materials was investigated.

\section{Materials and Methods}

\subsection{Chemicals and materials}

The materials used in the synthesis were kaolin waste from the tailings pond of an industrial facility in the Amazon region, orthophosphoric acid $(85 \%)$ (Neon), morpholine $\left(\mathrm{C}_{4} \mathrm{H}_{9} \mathrm{NO}, \mathrm{MW}=87.1 \mathrm{~g} / \mathrm{mol}, \mathrm{EP}=129^{\circ} \mathrm{C}\right)($ Synth $)$, calcined aluminium hydroxide (Synth), and distilled water.

\subsection{Synthesis of SAPO-34 samples}

The process was initiated by calcination of the kaolin waste at $700{ }^{\circ} \mathrm{C}$ for $2 \mathrm{~h}$. SAPO-34 was prepared via a hydrothermal route with two molar ratios of $\mathrm{SiO}_{2} / \mathrm{Al}_{2} \mathrm{O}_{3}$ The first considered the ratio of the industrial waste itself $\left(\mathrm{SiO}_{2} / \mathrm{Al}_{2} \mathrm{O}_{3} \sim 2\right)$, and the second considered the compensation of the aluminium, performed by the insertion of aluminium hydroxide calcined at $700{ }^{\circ} \mathrm{C}$ to meet the requirements for the synthesis composition established by the International Zeolite Association (IZA), which for SAPO-34 is $\mathrm{Al}_{2} \mathrm{O}_{3}: 1.08 \mathrm{SiO}_{2}: 1.06 \mathrm{P}: 2 \mathrm{R}: 66 \mathrm{H}_{2} \mathrm{O}$ in which $\mathrm{R}$ is the SDA. This study used morpholine as the SDA. Both methodologies were initiated with a mixture of metakaolin and morpholine, followed by the addition of phosphoric acid, distilled water, and calcined aluminium 
hydroxide when necessary. The system was agitated for $4 \mathrm{~h}$ and then sealed in an autoclave made of steel internally coated with PTFE at $200{ }^{\circ} \mathrm{C}$ at different time intervals. After the crystallization time, the autoclave was cooled to room temperature, and the synthesis products were filtered and washed until they achieved neutral $\mathrm{pH}$ and dried at $105^{\circ} \mathrm{C}$ for $24 \mathrm{~h}$.

\subsection{Characterization}

All samples were characterized using X-ray fluorescence (XRF, PANalytical), X-ray diffraction (XRD, $\mathrm{K} \alpha \mathrm{Cu}$, Bruker), scanning electron microscopy (SEM, TESCAN), and thermogravimetric analysis (TGA), NETZSCH STA 449F3).

\section{Results and Discussion}

\subsection{Characterization of the kaolin and metakaolin waste}

The chemical composition of the industrial kaolin waste was obtained by XRF, and the material consisted mainly of silicon oxide (47.3\%) and aluminium (37.0\%). The iron and titanium oxides were also observed in percentages of $1.03 \%$ and $0.83 \%$, respectively, with a loss on ignition of $13.84 \%$.

The direct use of kaolin waste in the synthesis of molecular sieves was not indicated because the material was stable and led to the formation of structures with different crystalline phases and a very significant amount of amorphous material. Thus, it was necessary to modify the kaolin waste for its activation. This procedure was performed through a calcination process, which promoted rupture of the kaolinite structure, transforming it into an amorphous material a metakaolin more reactive material than the original material ${ }^{11}$.

Figure 1 shows the diffractograms related to the kaolin and metakaolin wastes produced. The waste is characterized by the presence of peaks at the $12.4^{\circ}$ and $24.9^{\circ}$ positions, which are attributed to kaolinite (ICDD 01-083-0971), and the occurrence of anatase was also observed (ICDD 00-004-0477). The presence of anatase is common in kaolin in the Amazon region and is considered an impurity in the final product. Thus, separation occurs during processing, and anatase is released into the tailing ponds ${ }^{12}$. The transformation of kaolin into metakaolin necessary for its activation was observed by the XRD data, and the results are presented in Figure 1. The calcination step proved to be efficient, and the complete destruction of the kaolinite structure by the dehydroxylation reaction was observed; consequently, an amorphous material characterized by an elevation of the diffractogram background was produced ${ }^{10,12}$.

Figure 2 presents the results obtained by the (Termogravimetry analysis) TGA and DSC analyses of the kaolin waste, and three thermal events are observed in the material: i) loss of mass starting at $\sim 100^{\circ} \mathrm{C}$ attributed to moisture loss, followed by loss of mass until approximately $350^{\circ} \mathrm{C}$ due to dehydration of the material; ii) the largest loss of mass ( $\sim 13.84 \%)$ at $514{ }^{\circ} \mathrm{C}$, indicated in the DSC curve, characterized by an endothermic peak (kaolinite dehydroxylation occurs in this region, transforming its structure into metakaolinite); and iii) an exothermic peak observed at $980^{\circ} \mathrm{C}$, indicating the formation of a new crystalline phase (mullite) ${ }^{10,12}$.

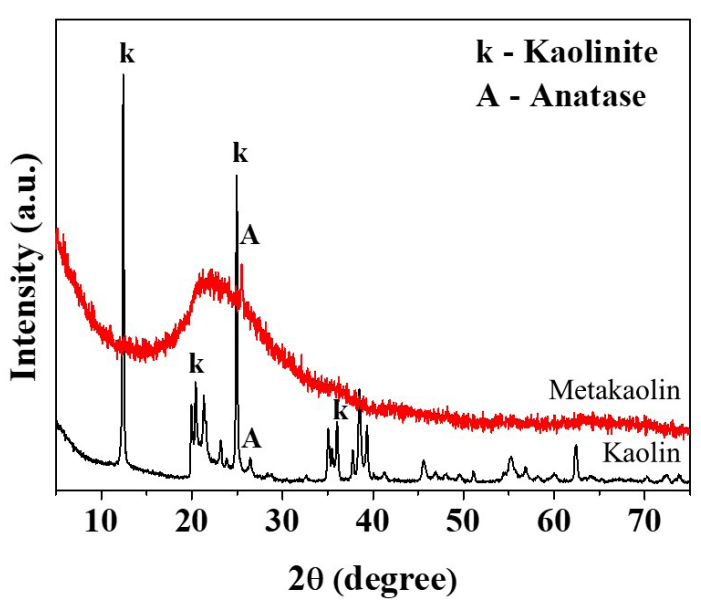

Figure 1. XRD kaolin and metakaolin.

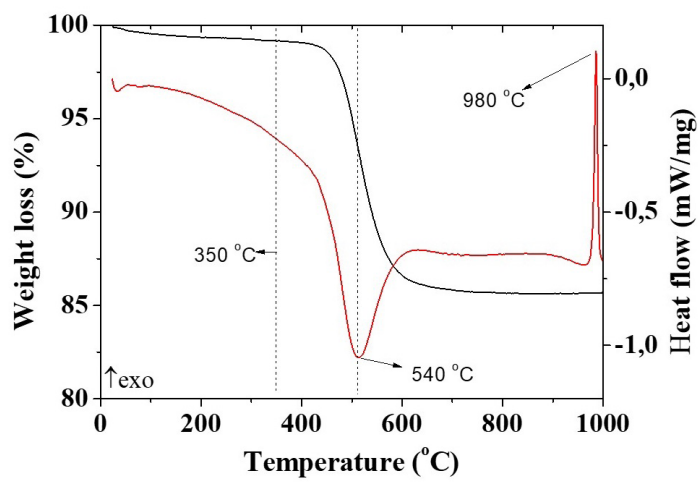

Figura 2. Termogravimetry analysis (TGA) and differential scanning calorimeter (DSC) waste.

Micrographs of the industrial waste from produced kaolin and metakaolin are shown in Figure $3 \mathrm{a}$ and $3 \mathrm{~b}$, respectively. For the industrial kaolin waste, pseudo-hexagonal clusters are observed, which characterize the presence of kaolinite, while for the metakaolin sample (red arrow) (Figure 3b) these clusters separated, and pseudo-hexagonal morphologies were preserved ${ }^{13}$.

\subsection{Evaluation of crystallization time and $\mathrm{SiO}_{2} / \mathrm{Al}_{2} \mathrm{O}_{3}$ ratio}

Figure 4 a shows the $\mathrm{X}$-ray diffraction of synthesis that used the ratio of $\mathrm{SiO}_{2} / \mathrm{Al}_{2} \mathrm{O}_{3} \sim 2$ originating from the kaolin waste itself. It is observed that during the first $5 \mathrm{~h}$ of crystallization, there was only the ALPO phase (ICDD 00-043-0563) and a significant amount of amorphous material. SAPO-34 was obtained only after $48 \mathrm{~h}$ of crystallization, in which the ALPO phase disappeared, and the amorphous material decreased. These results can be attributed to the formation mechanism of silicophosphates (SAPO), which are produced by the incorporation of silicon into the aluminophosphate (ALPO) structure, which can basically occur by three mechanisms: $\mathrm{SM} 2\left(\mathrm{Si}^{4+} \rightarrow \mathrm{P}^{+5}\right)$, SM3 $\left(2 \mathrm{Si}^{4+} \rightarrow \mathrm{Al}^{3+}+\mathrm{P}^{+5}\right)$, or a combination thereof. It is noteworthy that the insertion and distribution of Si in the ALPO structure is one of the main parameters that determine the final acid strength of the material and, consequently, its application ${ }^{14}$. Furthermore, the significant 

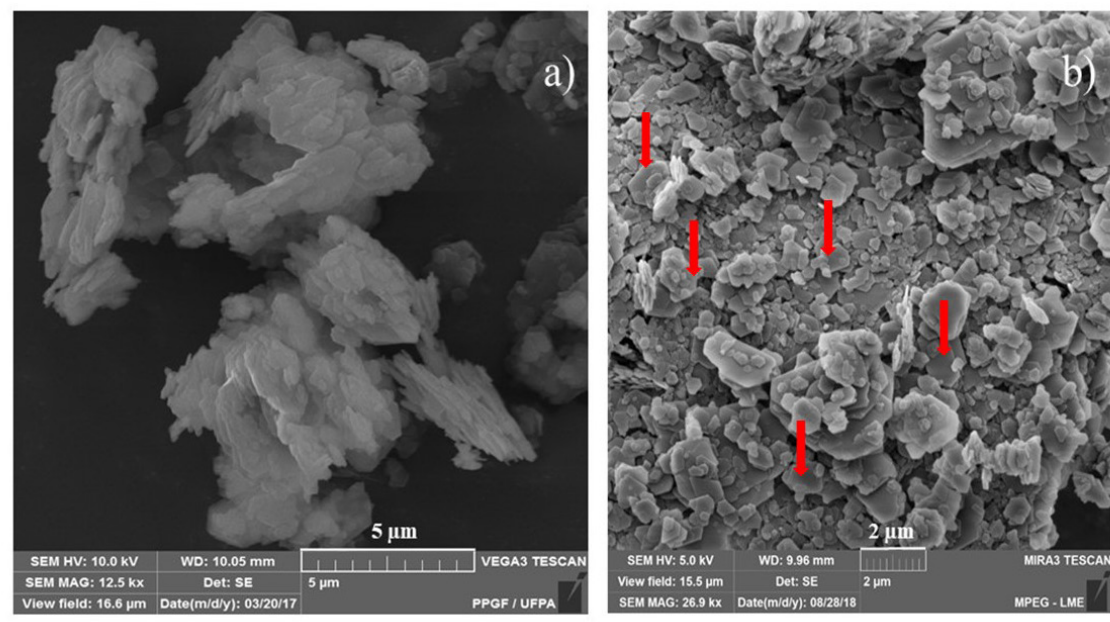

Figure 3. (a) kaolin waste; (b) metakaolin.

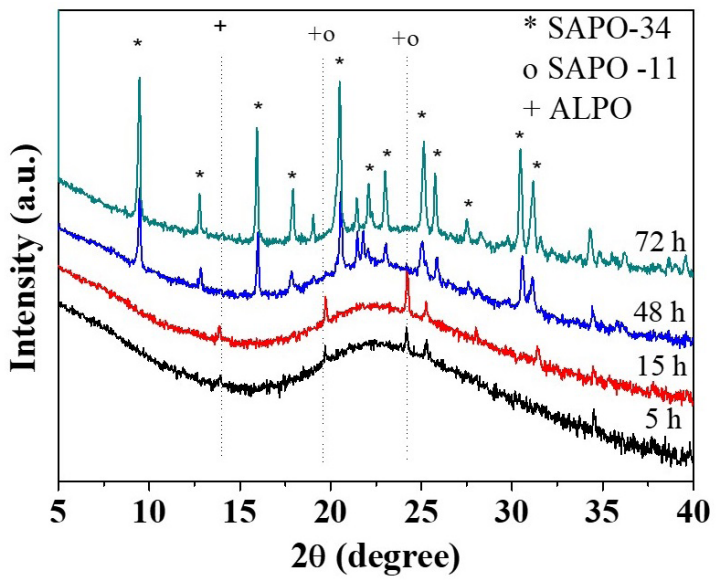

Figure 4. X-ray diffractograms of samples without adjustment of the $\mathrm{SiO}_{2} / \mathrm{Al}_{2} \mathrm{O}_{3}$ ratio.

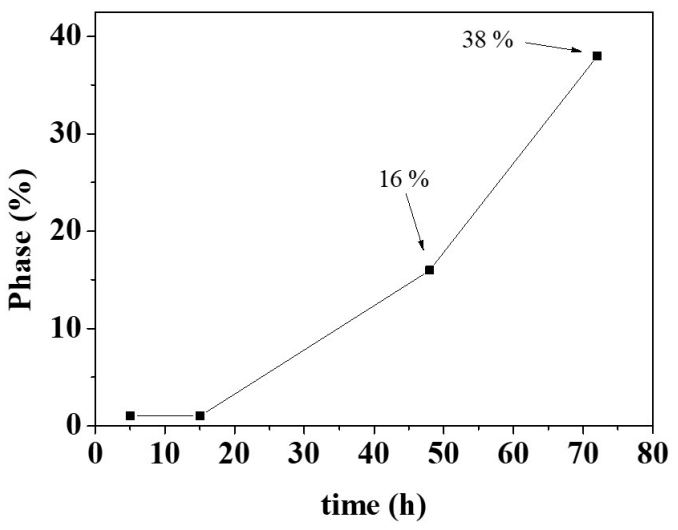

Figure 5. \% phase formed as a function of crystallization time.

presence of non-crystallized (amorphous) material is attributed to the high percentage of silicon in relation to the $\mathrm{Al}$ and $\mathrm{P}$ atoms in the reaction mixture, which results in an incomplete process of incorporation ${ }^{7,8,15}$ and production of

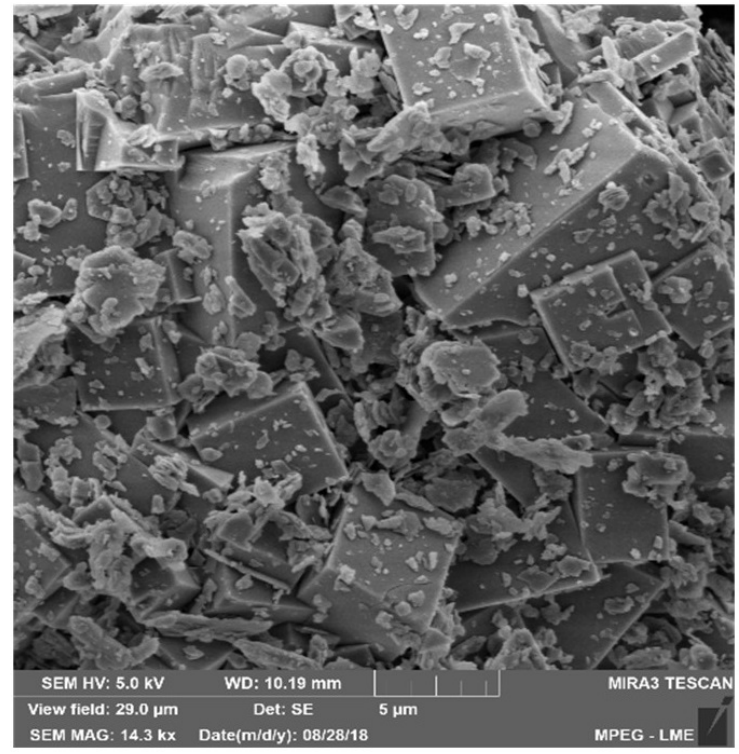

Figure 6. SEM $72 \mathrm{~h}$ without adjustment of the $\mathrm{SiO}_{2} / \mathrm{Al}_{2} \mathrm{O}_{3}$ ratio.

secondary phases such as SAPO-11 (ICDD 00-046-0647) observed in the $48 \mathrm{~h}$ and $72 \mathrm{~h}$ samples.

The phases percentage as a function of crystallization time was roughly calculated according to the methodology described in ${ }^{16}$ with modifications, with the results shown in Figure 5. The formation of SAPO-34 is favored when the crystallization time is increased, which in the time of $72 \mathrm{~h}$ already only observes the formation of the crystalline phase SAPO-34. However, it is $38 \%$ pure mainly due to the presence of amorphous material.

Figure 6 shows the micrograph of the synthesis without adjustment for $72 \mathrm{~h}$. The presence of material with the cubic morphology characteristic of SAPO-34 (ICDD00-047-0429) can be observed; however, there is a significant amount of non-crystallized material, as observed by the XRD data.

Figure 7 present the XRD results of the samples with the ratio of $\mathrm{SiO}_{2} / \mathrm{Al}_{2} \mathrm{O}_{3} \sim 1$ adjusted by the addition of 


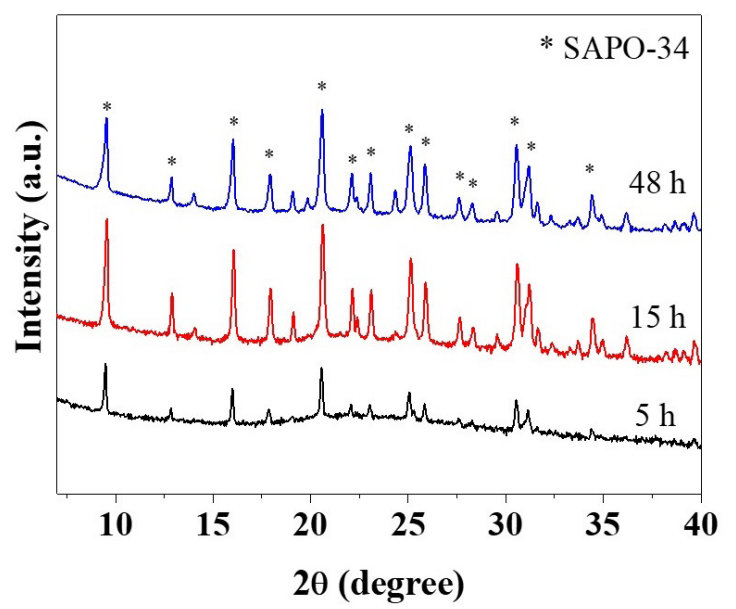

Figure 7. X-ray diffraction with adjustment of the $\mathrm{SiO}_{2} / \mathrm{Al}_{2} \mathrm{O}_{3}$ ratio.

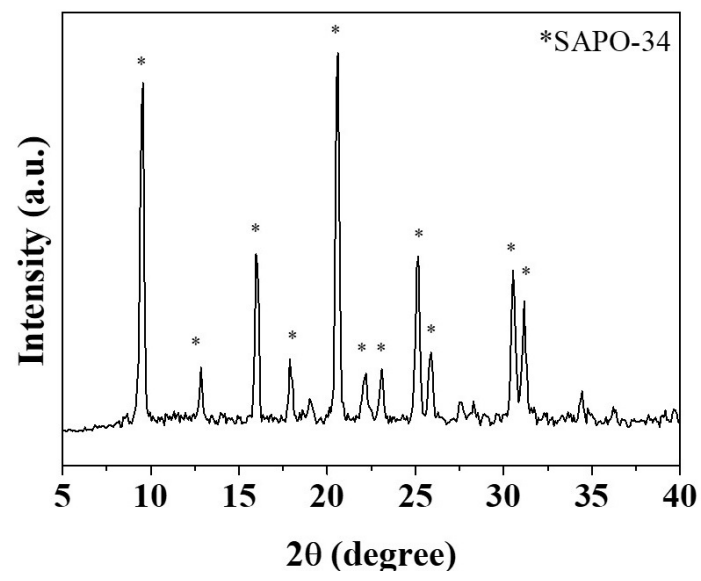

Figure 8. $72 \mathrm{~h}$ with adjustment of the $\mathrm{SiO}_{2} / \mathrm{Al}_{2} \mathrm{O}_{3}$ ratio. aluminium in the synthesis gel. By comparing these results with those shown in Figure 2a, the adjustment of the ratio promotes the insertion of $\mathrm{Si}$ into the SAPO-34 structure, which is characterized by a sharp decrease of the background and consequent decrease of the amorphous material. The adjustment of the $\mathrm{SiO}_{2} / \mathrm{Al}_{2} \mathrm{O}_{3}$ ratio also accelerates the incorporation reaction of $\mathrm{Si}$ into the ALPO structure because the SAPO-34 structure was observed with the chabazite structure (CHA) in all studied crystallization times.

The influence of crystallization time on phase is best observed by comparing the data shown in Figure 7 and 8 . The use of the longer crystallization time of $72 \mathrm{~h}$ promoted a significant increase in the intensity of the peaks corresponding to the SAPO-34 phase (Figure 8); in addition, no significant elevation of the background was observed (characteristic of amorphous material). Thus, there was a final material with high phase crystallinity and purity, as also observed in ${ }^{17,18}$.

Figure 9 shows the micrographs obtained for the samples with the ratio of $\mathrm{SiO}_{2} / \mathrm{Al}_{2} \mathrm{O}_{3} \sim 1$, for which cubic morphologies are observed in all cases (red arrows), which is characteristic of SAPO-34; however, there is a small amount of metakaolin because the crystallization time is still not sufficient for the formation of the material. As time advanced, as observed in Figure 9a-d, the amount of non-crystallized material decreased, increasing the formation of cubes characteristic of SAPO-34.

The crystallization percentage as a function time for the synthesis with $\mathrm{SiO}_{2} / \mathrm{Al}_{2} \mathrm{O}_{3}$ ratio was adjusted was determined through the methodology described in Bakhtiar et al. ${ }^{16}$, with changes considering the peak and background area. The obtained curve is shown in Figure 10 in which the highest crystallinity was approximately $98.6 \%$ for the $72 \mathrm{~h}$ period.

For the use of this material, its calcination is often necessary to promote pore clearance. Thus, the sample with the best crystallinity and purity result was determined by

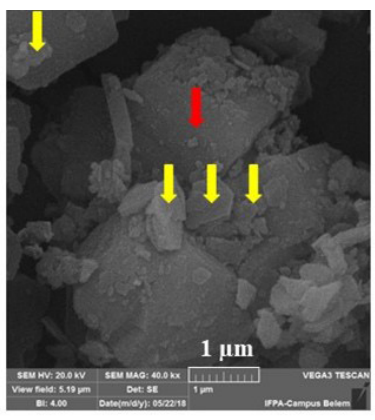

a)

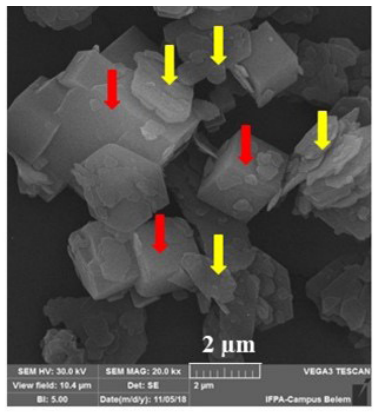

b)
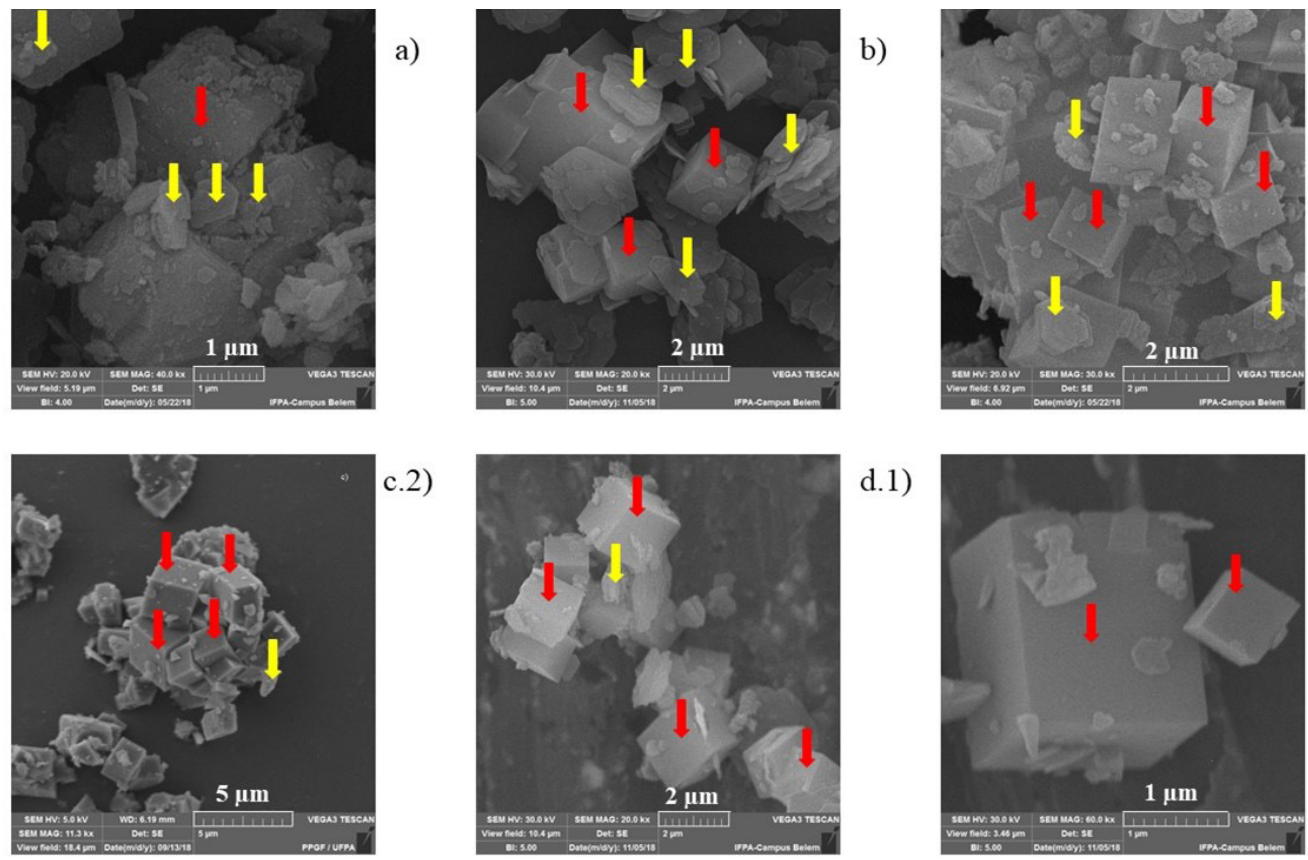

c.2)

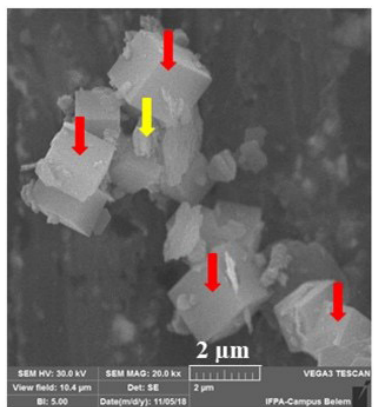

d.1)

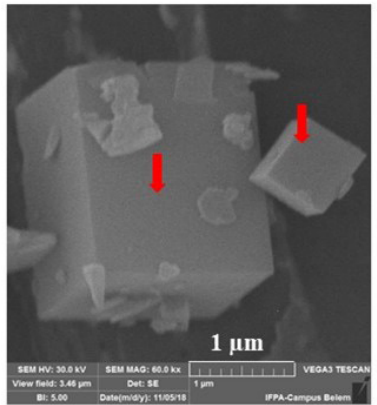

Figure 9. Micrographs of the samples with adjustment of the $\mathrm{SiO}_{2} / \mathrm{Al}_{2} \mathrm{O}_{3}$ ratio at (a) $5 \mathrm{~h}$; (b) $15 \mathrm{~h}$; (c.1; c.2) $48 \mathrm{~h}$, and (d.1; d.2) $72 \mathrm{~h}$. 


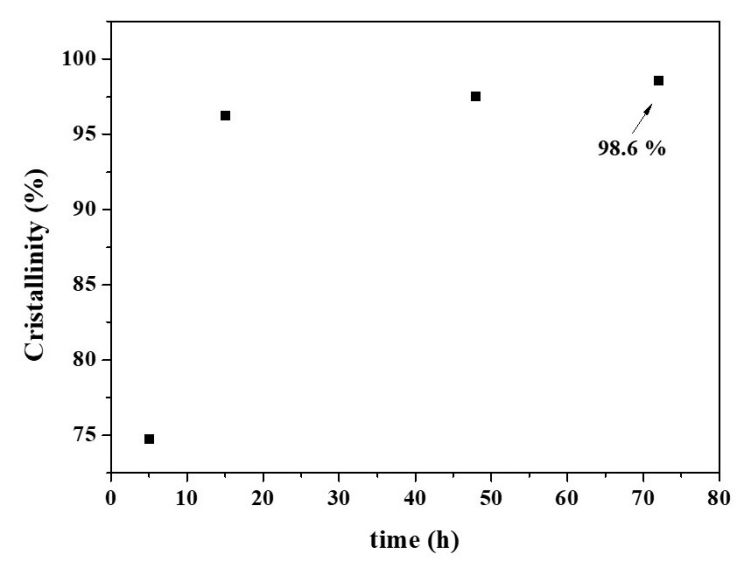

Figure 10. Crystallinity (\%) as a function time.

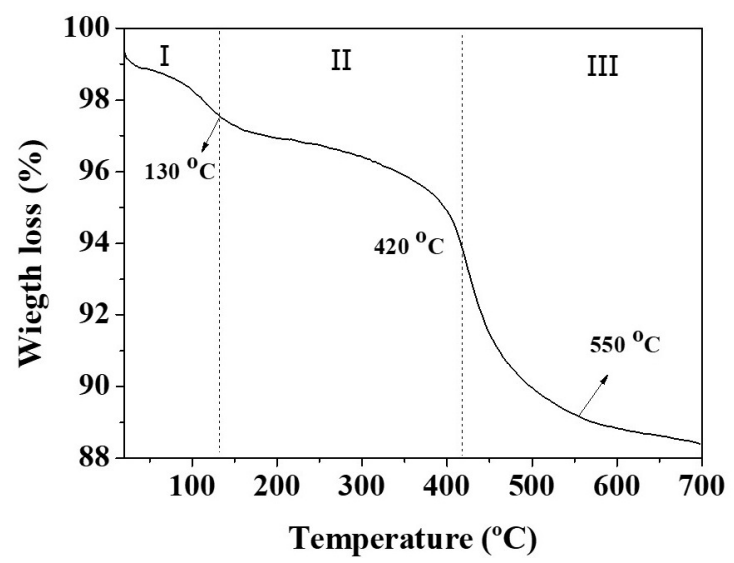

Figure 11. (a) TGA 48 and $72 \mathrm{~h}$ with adjustment.

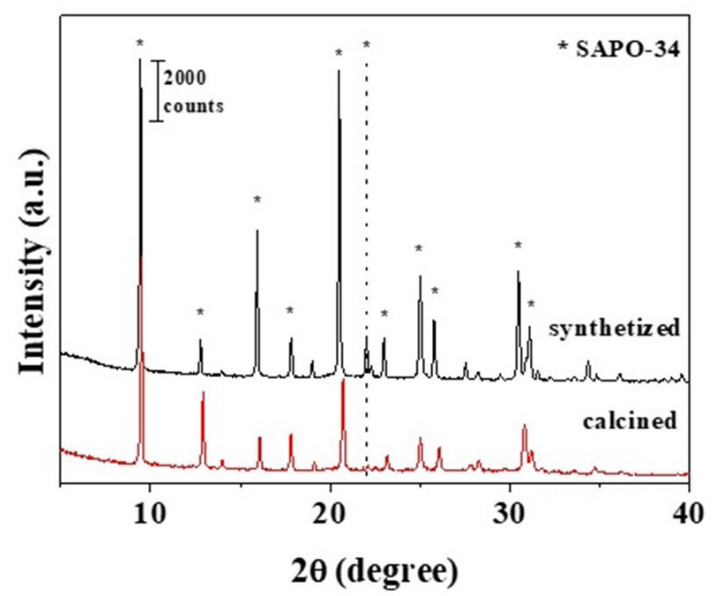

Figure 12. X-ray diffractograms, synthesis of $72 \mathrm{~h}$ with adjustment without calcination and after calcination.

verifying the thermal stability of its structure with the results obtained in Figure 11, 12 and 13.

The thermogravimetric analysis of the material is presented in Figure 11, in which three thermal events are observed: event I was related to water desorption from the surface of the material and hydration water occurring up to $\sim 130{ }^{\circ} \mathrm{C}$ ( 2\%); event II ( $3 \%)$ started at approximately $170^{\circ} \mathrm{C}$ and

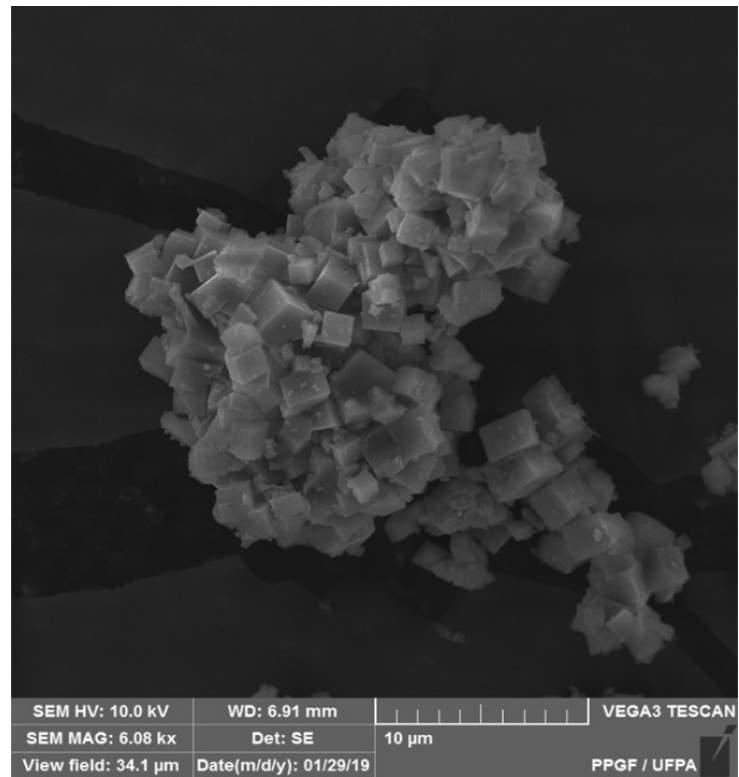

Figure 13. SEM of the calcined product.

was attributed to the decomposition of the SDA (morpholine) and extended to $\sim 420^{\circ} \mathrm{C}$; and event III $(\sim 5 \%)$, originating after $420^{\circ} \mathrm{C}$, was attributed to the volatilization of SDA waste ${ }^{7.8}$. Thus, it was concluded that the calcination temperature of $550^{\circ} \mathrm{C}$ was sufficient for the complete elimination of the produced materials.

Figure 12 shows the diffractograms of the samples produced by adjusting the $\mathrm{SiO}_{3} / \mathrm{Al}_{2} \mathrm{O}_{3}$ ratio and crystallization time of $72 \mathrm{~h}$ before and after the calcination process, which was performed at $550^{\circ} \mathrm{C}$ for $3 \mathrm{~h}$ in the static regime. The reduction in peak intensity in the calcined diffractogram shows a decrease in the material crystallinity. However, even though the peak intensity decreased, the molecular sieve structure remained intact, demonstrating that it had good thermal resistance. This result was also observed by Agarwal et al. ${ }^{19}$, who used a calcination temperature of $540^{\circ} \mathrm{C}$ under airflow. The mass yield of the synthesis was calculated based on the initial load of metakaolin, phosphoric acid and compensator of the $\mathrm{Si} / \mathrm{Al}$ ratio with the final mass of the product obtained after calcination, reaching a yield of approximately $94.5 \%$.

The micrograph shown in Figure 13 is related to the calcined sample, and the presence of cubic morphologies can be observed, demonstrating that even after thermal treatment, the sieve structure was preserved.

\section{Conclusion}

Industrial kaolin waste can be used as a low-cost alternative for the synthesis of SAPO-34. This molecular sieve was synthesized as the majority crystalline phase when the synthesis occurred with the adjustment of the $\mathrm{SiO}_{2} / \mathrm{Al}_{2} \mathrm{O}_{3}$ ratio to $\sim 1$. When this occurs, the crystallinity of the material is high, and better formation is observed as the reaction time increases.

The thermal stability of the sample crystallized for $72 \mathrm{~h}$ was confirmed, in which the process of calcination at $550^{\circ} \mathrm{C}$ 
is sufficient to promote the cleaning of the material pores by eliminating the structure directing agent and its waste. Furthermore, the material produced maintained its crystalline structure after calcination, which demonstrates good thermal resistance, and it can be used for future catalytic applications and sorption processes.

\section{Acknowledgements}

The authors acknowledge the XDR Analysis Laboratory-PPGF-UFPA network, metallurgy laboratory-IFPA, and Mineral Characterization Laboratory-IG/UFPA for the support of the facilities used in this work. This work has been mainly supported by FINEP, CNPQ, CAPES, and FAPESPA.

\section{References}

1. Liu G, Tian P, Zhang Y, Li J, Xu L, Meng S, et al. Synthesis of SAPO-34 templated by diethylamine: crystallization process and $\mathrm{Si}$ distribution in the crystals. Microporous Mesoporous Mater. 2008;114(1-3):416-23. http://dx.doi.org/10.1016/j. micromeso.2008.01.030.

2. Xing A, Yuan D, Tian D, Sun Q. Controlling acidity and external surface morphology of SAPO-34 and its improved performance for methanol to olefins reaction. Microporous Mesoporous Mater. 2019;288:109562. http://dx.doi.org/10.1016/j. micromeso.2019.109562.

3. Zhang SZ, Wen Z, Yang L, Duan C, Lu X, Song Y, et al. Controllable synthesis of hierarchical porous petal-shaped SAPO-34 zeolite with excellent DTO performance. Microporous Mesoporous Mater. 2019;274:220-6. http://dx.doi.org/10.1016/j. micromeso.2018.08.001.

4. Han S, Cheng J, Ye Q, Cheng S, Kang T, Dai H. Ce doping to $\mathrm{Cu}-\mathrm{SAPO}-18$ : enhanced catalytic performance for the NH3-SCR of NO in simulated diesel exhaust. Microporous Mesoporous Mater. 2019;276:133-46. http://dx.doi.org/10.1016/j. micromeso.2018.09.027.

5. Ahmad NNR, Leo CP, Ahmad AL. Effects of solvent and ionic liquid properties on ionic liquid enhanced polysulfone/SAPO34 mixed matrix membrane for $\mathrm{CO}_{2}$ removal. Microporous Mesoporous Mater. 2019;283:64-72. http://dx.doi.org/10.1016/j. micromeso.2019.04.001.

6. Liu B, Tang C, Li X, Wang B, Zhou R. High-performance SAPO-34 membranes for $\mathrm{CO}_{2}$ separations from simulated flue gas. Microporous Mesoporous Mater. 2020;292:109712. http:// dx.doi.org/10.1016/j.micromeso.2019.109712.

7. Wang Q, Wang L, Wang H, Li Z, Wu H, Li G, et al. Synthesis, characterization and catalytic performance of SAPO-34 molecular sieves for methanol-to-olefin (MTO) reaction. Asia-Pac J Chem Eng. 2011;6(4):596-605. http://dx.doi.org/10.1002/apj.453.
8. Singh AK, Yadav R, Sakthivel A. Synthesis, characterization, and catalytic application of mesoporous SAPO-34 (MESO-SAPO-34) molecular sieves. Microporous Mesoporous Mater. 2013;18:16674. http://dx.doi.org/10.1016/j.micromeso.2013.07.031.

9. Hildebrando EA, Angélica RS, Neves RF, Valenzuela-Diaz FR. Síntese de zeólita do tipo faujasita a partir de um rejeito de caulim. Ceramica. 2012;58(348):453-8. http://dx.doi. org/10.1590/S0366-69132012000400006.

10. Silva SH Fo, Bieseki L, Silva AR, Maia AAB, San Gil RAS, Pergher SBC. Synthesis of Zeolite A employing Amazon kaolin waste. Ceramica. 2015;61(360):409-13. http://dx.doi. org/10.1590/0366-69132015613601898.

11. Maia AAB, Alves MS, Angelica RS, Neves RF. Efeito do envelhecimento da mistura reacional constituída por resíduo de caulim da Amazônia na síntese da zeólita faujasita. Ceramica. 2017;63(368):485-9. http://dx.doi.org/10.1590/036669132017633682160

12. Santana DL, Saraiva ACF, Neves RF, Silva DL. Zeólita A sintetizada a partir de rejeitos do processo de beneficiamento de caulim. Ceramica. 2012;58(346):238-46. http://dx.doi. org/10.1590/S0366-69132012000200015.

13. Maia AAB, Saldanha E, Angélica RS, Souza CAG, Neves RF. Utilização de rejeito de caulim da Amazônia na síntese da zeólita A. Ceramica. 2007;53(327):319-24. http://dx.doi. org/10.1590/S0366-69132007000300017.

14. Tiuliukova IA, Rudina NA, Lysikov AI, Cherepanova SV, Parkhomchuk EV. Screw-like morphology of silicoaluminophosphate-11 (SAPO-11) crystallized in ethanol medium. Mater Lett. 2018;228:61-4. http://dx.doi.org/10.1016/j. matlet.2018.05.118

15. Yang H, Liu X, Lu G, Wang Y. Synthesis of SAPO-34 nanoplates via hydrothermal method. Microporous Mesoporous Mater. 2016;225:144-53. http://dx.doi.org/10.1016/j.micromeso.2015.12.017.

16. Bakhtiar SH, Ali S, Dong Y, Wang X, Yuan F, Li Z, et al. Selective synthesis of the SAPO-5 and SAPO-34 mixed phases by controlling $\mathrm{Si} / \mathrm{Al}$ ratio and their excellent catalytic methanol to olefins performance. J Porous Mater. 2018;25(5):1455-61. http://dx.doi.org/10.1007/s10934-018-0558-7.

17. Ye L, Cao F, Ying W, Fang D, Sun Q. Synthesis optimization of SAPO-34 in the presence of mixed template for MTO process. Adv Mat Res. 2010;132:246-56. http://dx.doi.org/10.4028/ www.scientific.net/AMR.132.246.

18. Li J, Li Z, Han D, Wu J. Facile synthesis of SAPO-34 with small crystal size for conversion of methanol to olefins. Powder Technol. 2014;262:177-82. http://dx.doi.org/10.1016/j. powtec.2014.04.082.

19. Agarwal K, John M, Pai S, Newalkar BL, Bhargava R, Choudary NV. SAPO-34 assisted C3 separation: modeling and simulation. Microporous Mesoporous Mater. 2010;132(3):311-8. http:// dx.doi.org/10.1016/j.micromeso.2010.02.024. 